\title{
Is it time to demand evidence-based advertising?
}

\author{
Salvador Israel Macías-Hernández ${ }^{1}$ and Juan Daniel Morones-Alba²
}

${ }^{1}$ Orthopedic Rehabilitation Division, Instituto Nacional de Rehabilitación; ${ }^{2}$ Military Odontology School, Universidad del Ejército y Fuerza Aérea Mexicana, Ciudad de México, Mexico

\begin{abstract}
Claims made in current advertising for medical products is not necessarily scientifically proven, yet at the same time clinicians are required to adopt evidence-based practices and undergo periodic certifications. This is a clear contradiction. It is crucial to begin to reflect on the need to regulate information presented in the media and to place greater emphasis on patient well-being and safety instead of on third-party interests. The medical community must demand stricter regulations and evidence-based advertising policies.
\end{abstract}

KEY WORDS: Consumer advertising. Evidence based medicine. Communications media.

In recent years, health-related products advertising has turned into a whirlwind of advertisements that fill consumers with information on the characteristics, pathophysiology and treatment of diseases. Many of these pathologies are highly prevalent, disabling and regarded as public health problems in Mexico and the world, and they imply multimillion costs for health systems, including diabetes, obesity or osteoarthritis, which are important causes of morbidity and mortality ${ }^{1}$.

In parallel, there are national and international medical societies, associations and institutions that are dedicated to diffuse evidence-based documents. These documents include clinical practice guidelines, evidence-based recommendations, broad literature reviews, exhaustive meta-analyses and large randomized, controlled clinical trials, which objectively and under strict scientific and methodologic control show the effects of different treatments. Guidelines and recommendations force the clinician to exercise his/her practice according to the principles of scientific knowledge. In addition, physicians undergo periodic evaluations by councils that certify their competence to practice the profession.
It is paradoxical that, on one hand, information in mass media is increasingly vast and superficial, that marketing strategies are used to emphasize on the "benefits" of products and invite to consume them owing to their curative, disease-modifying or symptom relief effects, which not necessarily are scientifically proven, without considering potential adverse reactions or risks with their use, and on the other hand, that physicians are mandated to adhere to evidence-based practice.

Every day, thousands of scientific studies are published on procedures, interventions, substances, drugs or supplements. Therefore, in parallel to the accelerated advance of evidence-based medicine and recommendations, mass media continue to diffuse information solely based on marketing strategies. Thus, just to quote an example, in a study carried out in Australia where the scientific evidence of information published in health dissemination magazines, only $36 \%$ of the presented information was found to be scientifically supported ${ }^{2}$.

Clearly, economic interests are put ahead best clinical practice, since many of the claims in advertising lack scientific support ${ }^{3}$.

\footnotetext{
Correspondence:

Salvador Israel Macías-Hernández

Calzada México-Xochimilco 289

Col. Arenal de Guadalupe, Del. Tlalpan

C.P. 14389, Ciudad de México, México

E-mail: simacias@inr.gob.mx, drisraelmacias@gmail.com
}

Date of reception: 06-01-2017

Date of acceptance: 11-01-2017

DOI://dx.doi.org/10.24875/GMM.M18000093
Gac Med Mex. 2017;153:825-826

Contents available at PubMed www.gacetamedicademexico.com 
Unfortunately, in the advertising market there are, just to mention a few, products for weight control; "modifiers of disease progression or regenerators" for conditions such as osteoarthritis; "natural" substances against depressive symptoms; substances that control diabetes and its complications; and over-the-counter analgesics and anti-inflammatory drugs that do not consider patient morbidities such as gastropathies, heart conditions or high blood pressure, the effects of which might not only be inefficacious, but potentially serious or even life-threatening ${ }^{4}$. There are cases of lack of government regulation where some "miracle" products are approved without scientific support for the treatment of diseases such as cancer ${ }^{5}$.

There is a clear end evident need for medical advertising to be regulated, which should be invariably supported by scientific evidence of adequate quality and unquestionable reliability, as well as for patients' wellbeing and interests to be put ahead of those of everyone else.

\section{References}

1. Lozano R, Naghavi M, Foreman K, et al. Global and regional mortality from 235 causes of death for 20 age groups in 1990 and 2010: a systematic analysis for the Global Burden of Disease Study 2010. Lancet. 2012;380:2095-128.

2. Wilson $A$, Smith $D$, Peel $R$, et al. A quantitative analysis of the quality and content of the health advice in popular Australian magazines. Aust N Z J Public Health. 2017;41:256-8.

3. Gale DA. The focus of the media is medical intervention not the pursuit of health. PLoS Med. 2005;2:e362.

4. Schwitzer G, Mudur G, Henry D, et al. What are the roles and responsibilities of the media in disseminating health information? PLoS Med. 2005;27:e215.

5. Kuchenbecker RS, Mota DM. Miracle drug: Brazil approves never-tested cancer medicine. J Oncol Pharm Pract. 2017;23:399-400. 